\title{
Exploring the Use of Rubrics as a Self Assessment Tool for Pre-service Teachers
}

\author{
Somyata Gupta and Sangeeta Chauhan
}

\begin{abstract}
Evaluating students constructively through a host of self-assessment tools can help create engaged and committed learners which are a requisite for the current educational scenario. This study was attempted in an English writing class at a Pre-Service Teacher Education Institution in India to deconstruct the significance of rubrics as a self-assessment tool leading to the attainment of better learning experiences. For an empirical investigation of relationships between variables, the authors designed a Rubric Table, collected data using a Questionnaire and conducted a statistical analysis of the responses recorded. Preliminary findings suggested that students believed the process of teaching-learning to be more empowering and structured as rubrics not only enhance student learning but also involve the elimination of failure by asserting that every learner can succeed. Rubrics, thus are a functional tool that offer room for reflection and selfindependent learning.
\end{abstract}

Index Terms-Pre-service teachers, rubrics, self assessment, teacher education.

\section{INTRODUCTION}

Self Assessment as a progressive approach to learning can be understood as a process wherein students (a) discern strategies for enhanced understanding of the subject taught and (b) assess and analyze the peculiarities of their thinking and learning.

Expansively acknowledged by educators for assessment purposes, rubrics are referred to as an instructional tool that enables students to engage in constructive self-feedback [1]. They articulate expectations for student work by listing criteria for the work and performance level descriptions across a continuum of quality [2].

Thus, the criteria that state what to look for in the work and performance level descriptions that outline the knowledge, skills and practices that students achieve at the said level form the bases of assessing student learning.

Empirical research on the efficacy of assessment rubrics has chiefly focused on its contribution towards enhancement of academic performance as observed in the consummation of higher grades. The present study aims to explore the use of rubrics as a self-assessment tool for pre-service teachers and addresses the following research objectives such as;

- To deduce that assessment rubrics promote reflective learning and lead to the development of self-directed learners.

Manuscript received on March 14, 2020; revised June 7, 2020

Somyata Gupta and Sangeeta Chauhan are with University School of Education, Guru Gobind Singh Indraprastha University, New Delhi 110078 , India (e-mail: somyatagupta@yahoo.in, chauhan.dr@gmail.com).
- To determine that using rubrics makes assessment more consistent, efficient, objective and improves the students' academic performance.

- To determine that introduction to the rubric table generates learning that is intentional and purposeful.

\section{OPERATIONAL DEFINITIONS}

\section{A. Rubrics}

A rubric is a guiding resource used by educators that lays out the expectations for an assignment along with providing scaled levels of achievement for a given type of performance.

\section{B. Self Assessment}

Self Assessment allows time for students to pause, process, reflect and learn. When implemented in the right spirit, self-assessment can surely stimulate an inclination towards learning the practical application of the subject, making learning more meaningful, and guide students to themselves formulate their next learning steps.

\section{Pre-service Teacher Education}

Pre- Service teacher education, also called initial teacher education is a program of study that enriches potential teachers with all the necessary experience and abilities, thus developing a contemporary pedagogical philosophy that will render them capable of carrying out their job efficiently.

\section{RELATED LITERATURE}

Wolf and Stevens [3] in their study reinforce that assessment rubrics not only enhance student learning, result in improvisation of teaching strategies, provide constructive and meaningful feedback to learners and pave way for purposeful assessment following student learning outcomes; but also are a relevant source of information for program improvement.

Hudson [4] articulates that the primary hypothesis of outcome-based assessment involves the elimination of failure by asserting that every learner can succeed. Although all forms of assessment are known to have advantages and disadvantages of their own, assessment tools like rubrics provide greater scope for evaluating learners at various levels of competencies.

According to Reddy [5], using rubrics at higher education level in the USA results in improved academic performance, enhancement of motivation and development of selfdirected learners. Other than being a constructive tool for recording student achievement, rubrics also concentrate on guiding teachers about the course development, thus leading 
to their professional growth.

Winterscheid [6] demonstrates that college students are receptive to feedback and desire to apply it while attempting their future assessments. Rubrics function as a selfassessment tool for evaluating the performance of students, thus providing concrete evidence about their strengths and weaknesses.

Wei and Pecheone [7] investigate that recent changes in the evaluation system have forced teacher education programs to employ performance-based assessments that determine teachers' competencies for their professional development.

\section{RESEARCH METHODOLOGY}

\section{A. Research Design}

The research is quasi-experimental in nature. A timeseries design has been adopted wherein the researchers have attempted to study the effects of the treatment of assessment rubrics on students' learning over 6 weeks.

\section{B. Sample}

Using a simple random sampling technique, 40 preservice teachers have been selected as participants and data are drawn from a researcher designed rubric table, preexperimental and post-experimental articles written by the participants and a questionnaire.

\section{Delimitation}

The following delimitation is taken into consideration while conducting the present study:

- The study is delimited to one pre-service teacher education institution in Delhi.

- The sample frame includes students of the first year of Bachelor of Education program.

- The sample size taken will be 40 pre-service teachers.

\section{Tools}

A researcher designed Analytic Rubric table has been used that provides distinct scoring of specified criterion that the sample is going to be assessed on. The rubric table has been tailor-made to meet the students' identified needs as against adopting an already existing one. This offers the researchers the scope of editing and improving the rubric table organically to enable the participants for the attainment of enhanced consistency and efficiency.

A researcher constructed Closed-ended Questionnaire comprising eight questions have been selected as a major source of evidence for research in this study. The rationale behind the construction of the questionnaire was to explore the students' perceptions about the use of rubrics while attempting an English writing assignment.

\section{E. Measures}

1) Pre-Experimental phase: The researchers divided the sample of 40 participants in groups of 5 each and instructed them to write an article on the topic 'Should single-use plastic be banned?' The researchers then directed the sample to self assess their performance on four criteria, namely Conceptualisation, Language Mechanism, Organisation and Word Choice without describing these criteria to them.

2) Treatment: The researchers then introduced the concept of rubrics to the sample and following a time series design, repeatedly made the sample practice writing on different themes and topics.

3) Post-Experimental phase: After 6 weeks, the researchers again asked the sample to write an essay on the same topic, 'Should single-use plastic be banned?' but after distributing among them the rubrics table. They were asked to follow the performance descriptors as described in the rubrics table and formulate their article based on the mentioned criteria. The researchers then asked the sample to self assess themselves on the criteria given to them, namely Conceptualisation, Language Mechanism, Organisation and Word Choice.

The sample was purposely given the same question before and after the treatment because the researchers intended to explore the use of rubrics as a self-assessment tool. The same question, thus, enabled the participants to self assess both their articles and helped the researchers in determining whether the use of rubrics indeed fosters students' ability in constructing a quality writing piece. The questionnaire was then distributed among the participants which required them to reflect upon their experiences with using assessment rubrics.

\section{DATA ANALYSIS AND RESUltS}

\section{A. Analysis}

In the present study, the data are collected using different tools following the laid down objectives. Analysis of the following tools is done - (a) participants filled Questionnaires (b) content analysis of the rubric table designed by the researchers and (c) pre-experimental and post-experimental articles written by the participants.

Upon analysis of the participant-filled questionnaires, the following information was derived as depicted in Fig. 1:

The researchers wanted to enquire how the participants felt about attempting an assessment using rubrics. 33 of the total 40 participants, i.e. $82.5 \%$ described it as objective and impartial.

The researchers wanted to ascertain if the assessment rubrics clarified the quality and the kind of work that was expected out of the sample. 33 of the total 40 participants, i.e. $82.5 \%$ concluded that rubrics gave them complete clarity of what exactly was expected out of their writing assignment.

The researchers wanted to probe if using assessment rubrics for writing an assignment influenced the creativity of the participants in any manner. 35 of the total 40 participants, i.e. $87.5 \%$ thought that introduction to the rubric table resulted in increased creativity.

The researchers wanted to enquire if assessment rubrics make the participants more confident to argue more effectively for having their work reassessed. 34 of the total 40 participants, i.e. $85 \%$ said they felt more empowered for their learning.

The researchers wanted to ascertain if the rubric table fostered an understanding of how the participants will begraded in the assignment. 35 of the total 40 participants, 
i.e. $87.5 \%$ said assessment rubrics were extremely helpful.

The researchers wanted to probe if the sample would prefer a writing assignment using assessment rubrics in the future. 23 of the total 40 participants, i.e. $57.5 \%$ said they would want to write an assignment using rubrics in the future.

The researchers wanted to enquire about the kind of grading system the participants found to be most efficient for a writing assignment. 30 of the total 40 participants, i.e. $75 \%$ preferred allotment of a grade along with a rubric.

The researchers wanted to ascertain how assessment rubrics affected the participants' learning. 30 of the total 40 participants, i.e. $75 \%$ said they had an enriched learning experience.

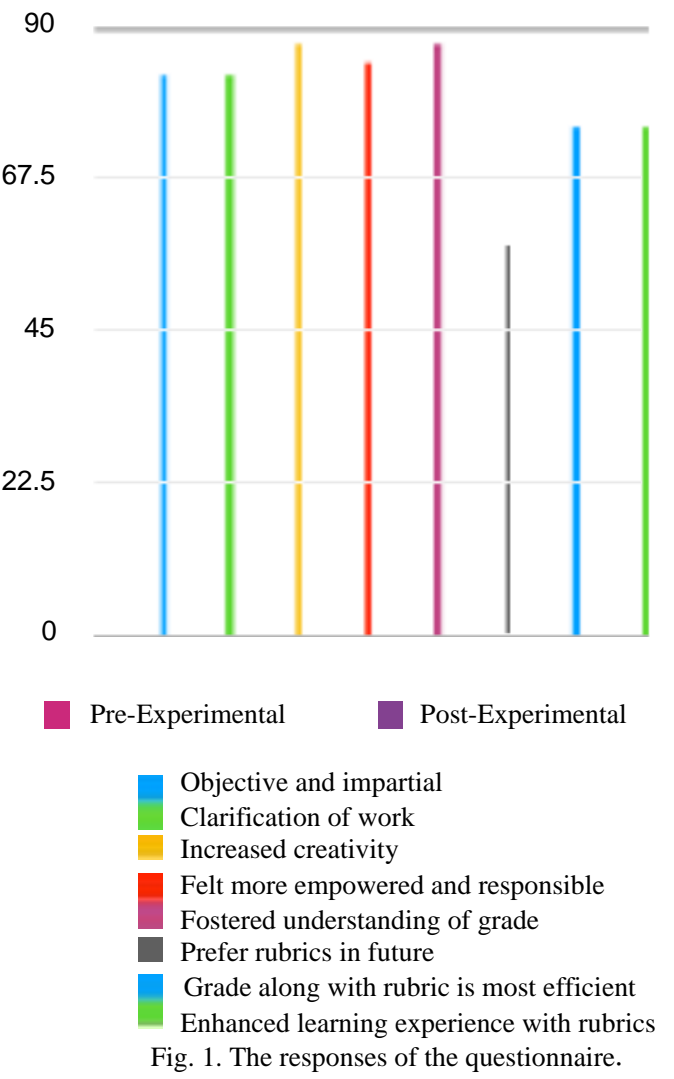

\section{B. Results}

1) To deduce that assessment rubrics promote reflective learning and lead to the development of selfdirected learners, the investigators statistically analyzed the participant-filled questionnaire distributed to them after the post-experimental phase (as shown in Appendix A). The following observations were made:

- Assessment rubrics are an effective way of conducting an objective and impartial assessment.

- Assessment rubrics give complete clarity about the parameters the students are going to be judged on, resulting in better learning outcomes.

- Assessment rubrics make the learners self-independent and responsible for their learning.

- Assessment rubrics make students clear about how they are going to be graded in the assignment and result in quality work.

- Grading along with rubrics is the most efficient form of marking a writing assignment.
- Assessment rubrics result in enriched learning and make learners more self-reliable.

2) To determine that using rubrics would make assessment more consistent, efficient, objective and improve students' academic performance, the investigators formulated a Writing Rubric Table that extensively demonstrated the criteria, the level of performance, the scores and the performance description the participants were to be assessed on. Content analysis of the rubric table (as depicted in Appendix B) was carried out by the researchers and the following observations were made:

The criteria of the Rubric table: Conceptualisation, Language Mechanism, Organisation and Word Choice deals with the traits, characteristics or the parameters which the writing assignment is to be assessed on. [8]

The Levels of performance: Exemplary, Capable, Developing and Beginning are the adjectives that ascertain the quality of performance of the participants.

The Scores of the Rubric table: 4, 3, 2 and 1 are the marks that align with the levels of performance.

The performance descriptors explain in detail what is expected out of the participants and how they would be scored.

3) To determine that introduction to the rubric table generates learning that is intentional and purposeful, the investigators analyzed both the pre-experimental and postexperimental articles written by the participants (as shown in Fig. 2).

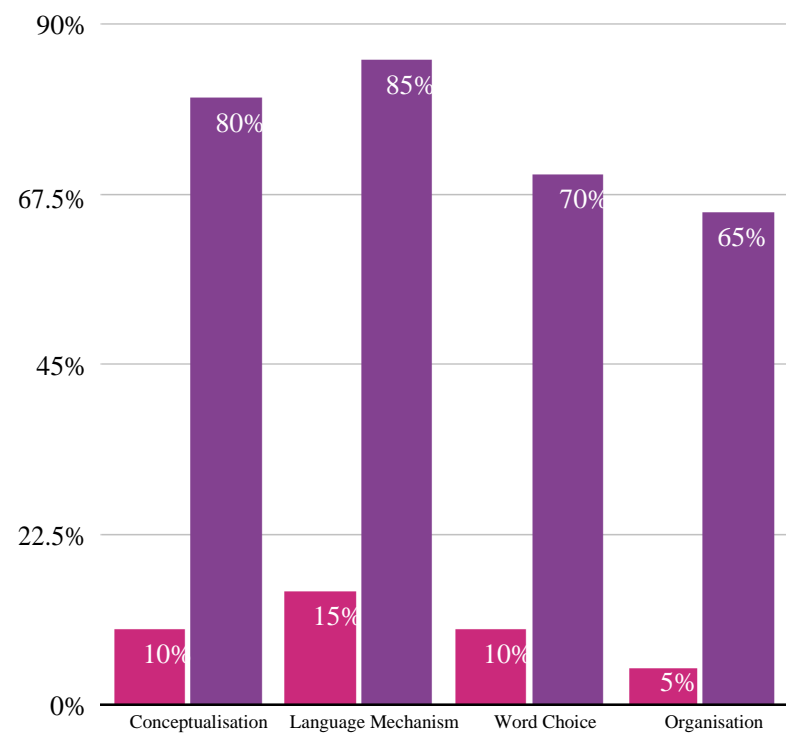

Fig. 2. Pre and post experimental articles.

The following observations were made:

- Development of the criterion Conceptualisation resulted in participants' increased engagement with the topic with $80 \%$ of the participants scoring an exemplary performance in the post-experimental phase as against only $10 \%$ in the pre-experimental phase.

- Formulation of the criterion Language Mechanism resulted in participants effectively using standard writing conventions for a quality writing piece. It was found that $85 \%$ of the participants scored an exemplary performance in the post-experimental phase whereas only $15 \%$ in the pre-experimental phase. 
- Inclusion of the criterion Word Choice resulted in participants using powerful, striking vocabulary, thus intending the meaning of the article. It was found that $70 \%$ of the participants scored an exemplary performance in the post-experimental phase whereas only $10 \%$ in the pre-experimental phase.

- Development of the criterion Organisation resulted in participants using competent organizational structure in their writing piece with $65 \%$ of them scoring an exemplary performance in the post-experimental phase as against only $5 \%$ in the pre-experimental phase.

\section{FINDINGS AND IMPLICATIONS}

After the analysis and interpretation of data, several findings of the research study were uncovered.

1) The investigators found that assessment rubrics allow participants sufficient time to self monitor their learning while staying focused on the skills the assignment aimed at developing [9]. Participants are better adept at giving themselves feedback when pre-determined criteria form the basis of their assessment [10]. The researchers also noticed that the detailed and descriptive feedback that assessment rubrics give to the participants results in deeper and lifelong learning.

2) It was found that using assessment rubrics in a writing assignment allows participants to know where they currently are, and how they can reach where they want to reach. Because rubrics help the participants in understanding the standard of work that is expected out of them, they can determine their further learning trajectory.

3) The researchers found that participants are better acquainted with the process of self-assessment of their current learning after the introduction of rubrics.

4) The investigators also found that participants employed strategies mentioned in the rubric table for surpassing their personal best and attaining mastery over the subject. Assessment rubrics function as a pioneer and a guiding resource to facilitate a relatively objective grading system. The rubric table well demonstrated the range of quality of the writing assignment, thus enabling the participants to understand the criteria on which they would be assessed, leaving little scope for inconsistency and subjectivity in grading them.

5) It was found that assessment rubrics support participants in building divergent approaches and perspectives, thereby influencing their creative thinking positively [11]. By listing an assignment as excellent, mediocre or in need of improvement, the participants can focus on the core concepts and standards which they consider necessary to obtain.

6) Acquainting participants with assessment rubrics before instruction and assessment drives them to reach for the level of performance expected, however, the investigators found that even though assessment rubrics generate constructive learning, the participants termed riting an assignment using them as complex and a timeconsuming process.

\section{CONCLUSION}

There are a variety of purposes underlying the conduct of Assessment: to promote achievement, literally translating to 'assessment of learning'; to promote learning, meaning 'assessment for learning'; and to entitle learners with the capacity to comprehend how they learn, exemplifying 'assessment as learning'.

Discernible matters of concern related to students' assessment and evaluation involve an insufficient explanation of evaluation criteria, differential observations, weakened relationship between learning targets and assessment, assessment for certification rather than mastery over a skill, and lack of timely and meaningful feedback. Restricting achievements to merely awarding certifications and degrees can limit the learner's potential to reflect on their learning. It is certainly not difficult to envision the persisting possibility of students' retreating to become passive learners.

Therefore, proactively shifting the focus of the students from excelling on paper to gathering flavors of rich learning experiences surmounted with a host of self-assessment activities is requisite for the current educational scenario. With a rush of learner-centric teaching-learning strategies, teachers have gradually acknowledged their role as facilitators of learning processes rather than deliverers of content. Hence, engaging learners in self-assessment provides them with the opportunity of receiving support rather than supervision from their teachers. Rich, comprehensive, and individually-suited timely feedback throughout the teaching-learning process - all accounts for active learning which enables students to make necessary modifications before it gets too late.

Here, the introduction of rubrics as an assessment procedure could promote the attainment of better learning outcomes as rubrics have demonstrated their effectiveness at heightening the reflection of students on their learning. Conducting an assessment using rubrics fosters problemsolving and critical-thinking skills among students and encourages them to learn in-depth rather than breadth. Using rubrics as a tool for self-assessment fosters students' ability to be the judge of their learning and identity the gaps and discrepancies prevailing between their present and desired performance. Rubrics, thus align with the concept of standards-based education, as they provide the learning targets, the criterion, and the performance descriptors that can facilitate student self-assessment.

\section{APPENDIX A}

Answer the following questions by reflecting upon your experiences with using assessment rubrics.

\section{A. How Would You Describe an Assessment Using Rubrics?}

- It was objective and impartial

- It was objective but not impartial

- It was impartial but not objective

- It was neither impartial nor objective

\section{B. How Far Did Assessment Rubrics Clarify What Was Expected out of You?}

- I had complete clarity about what was expected out of me 
- Assessment rubrics did not help in clarifying anything at all

- I had a lot of questions about what exactly had to be done

- Others

C. Did Rubrics Influence Your Creativity in Any Way?

- Rubrics led to increased creativity

- Rubrics resulted in decreased creativity

- Rubrics did not bring any difference in my creativity

D. Did Rubrics Make You Feel Confident to Argue More Effectively to Have Your Work Reassessed?

- I still felt the authority lies with the teacher

- I felt more empowered and responsible for my learning

- I felt under-confident about using rubrics for assessment

- Others

E. Did the Rubric Table Foster an Understanding of How You Will Be Graded in the Assignment?

- Yes, it was extremely helpful

- Yes, but it was only limited to a few parameters
- Rubrics did not help at all and only led to misunderstanding

F. Would you Prefer a Writing Skill Assignment with Rubrics in the Future?

- Yes, it results in enriched learning

- No, it is an extremely time-consuming process

- I might want to try it again

G. Which Kind of Grading Do You Now Find Most Efficient for a Writing Assignment?

- Only by grade

- Grade along with teachers' comments

- Grade along with a rubric

H. All in All, How Did Assessment Using Rubrics Affect Your Learning?

- I had an enhanced learning experience

- Using rubrics I felt a slight improvement in my learning

- Rubrics did not affect my learning at all

- Rubrics hampered my learning considerably

\section{APPENDIX B}

\begin{tabular}{|c|c|c|c|c|}
\hline SCORE POINT & EXEMPLARY(4) & CAPABLE (3) & DEVELOPING (2) & BEGINNING (1) \\
\hline $\begin{array}{l}\text { CONCEPTUAL } \\
\text { ISATION }\end{array}$ & $\begin{array}{c}\text { Authenticates penetrating } \\
\text { engagement with the topic or } \\
\text { argument, dissecting its multiple } \\
\text { dimensions with compelling, novel } \\
\text { examples. }\end{array}$ & $\begin{array}{r}\text { Demonst } \\
\text { purposefi } \\
\text { topic/argum } \\
\text { relev }\end{array}$ & $\begin{array}{l}\text { Presents } \\
\text { it lacks s } \\
\text { focus, an } \\
\text { for the }\end{array}$ & $\begin{array}{l}\text { Shows minimal understanding of the } \\
\text { topic as the readers must themselves } \\
\text { infer the theme based on sketchy and } \\
\text { unclear ideas that are not the author's } \\
\text { own. }\end{array}$ \\
\hline $\begin{array}{l}\text { LANGUAGE } \\
\text { MECHANISM } \\
\text { (Spelling, Grammar, } \\
\text { Paraphrasing, } \\
\text { Capitalisation, } \\
\text { Punctuation) }\end{array}$ & $\begin{array}{l}\text { Effective use of standard writing } \\
\text { conventions that enhance the } \\
\text { readability of the text which has } \\
\text { virtually no errors, thus making the } \\
\text { piece intriguing and look proofread. }\end{array}$ & $\begin{array}{l}\text { Production of a piece that is error- } \\
\text { free with very sporadic } \\
\text { inaccuracies in the standard } \\
\text { writing conventions, resulting in a } \\
\text { smooth read. }\end{array}$ & $\begin{array}{l}\text { Persistence of inconsistencies in the } \\
\text { standard writing conventions } \\
\text { throughout the text, thus restraining the } \\
\text { readers from gathering a complete } \\
\text { understanding of the text and } \\
\text { compelling them to unravel its } \\
\text { meaning. }\end{array}$ & $\begin{array}{l}\text { Predominance of } i \\
\text { the standard writin } \\
\text { Critically miscons } \\
\text { message of the tex } \\
\text { extensive a }\end{array}$ \\
\hline & $\begin{array}{l}\text { Competent organizational structure: } \\
\text { coherent progression, relevant to the } \\
\text { topic/ argument, convincing opening } \\
\text { and closing, effortless transitions } \\
\text { assisting in the comprehension of the } \\
\text { text. }\end{array}$ & $\begin{array}{l}\text { Methodical organizational } \\
\text { structure: mostly associated with } \\
\text { the topic/argument, supportive } \\
\text { opening and closing, a very rare } \\
\text { illogical progression of ideas, } \\
\text { adequate transitions linking } \\
\text { paragraphs but minor gaps } \\
\text { prevail. }\end{array}$ & $\begin{array}{l}\text { Limited organizational structure: hard } \\
\text { to build connections with the topic, } \\
\text { argument, unclear opening and closing, } \\
\text { poor flow of ideas and supporting } \\
\text { points, few evident transitions make the } \\
\text { piece difficult to understand. }\end{array}$ & $\begin{array}{l}\text { Inappropriate organizational structure: } \\
\text { not relevant to the topic/argument, } \\
\text { abrupt opening and closing, illogical } \\
\text { and unclear flow/ presentation of } \\
\text { ideas, lack of focused transitions } \\
\text { throughout the text. }\end{array}$ \\
\hline & $\begin{array}{l}\text { Use of powerful, striking } \\
\text { absolute and accurate } \\
\text { depth and convey the } \\
\text { meaning of the text spe }\end{array}$ & $\begin{array}{l}\text { Use of strong, "on- point" and } \\
\text { functional vocabulary, fluently } \\
\text { used words enrich writing and } \\
\text { communicate the message. Minor } \\
\text { errors in word formation/spelling } \\
\text { may exist. }\end{array}$ & $\begin{array}{l}\text { Use of understandable and basic } \\
\text { vocabulary, simple and limited variety } \\
\text { of words makes the piece a little } \\
\text { difficult to comprehend. Noticeable } \\
\text { errors may impede comprehension. }\end{array}$ & $\begin{array}{c}\text { Use of vague, repetitive, flawed } \\
\text { vocabulary, incorrect and unclear } \\
\text { words leave the reader confused and } \\
\text { may severely } \\
\text { distort the meaning of the text. }\end{array}$ \\
\hline
\end{tabular}

\section{CONFLICT OF INTEREST}

The authors declare no conflict of interest.

\section{AUTHOR CONTRIBUTIONS}

Somyata Gupta has conceptualised the study and designed the methodology of the research. She has formulated the Rubric Table, the Questionnaire and extensively worked on data analysis and interpretation of the results. Dr. Sangeeta Chauhan formulated the problem statement of the study and the literature review was done under her guidance. She also assisted in the review process throughout the development of the paper.

\section{REFERENCES}

[1] J. Uddin, Impact of the Use of Rubrics on the Performance of Students, BRAC Institute of Languages, 2017.
[2] S. Brookhart. (2018). Appropriate criteria: Key to effective rubrics. frontiers in education. [Online]. 3(22). Available: www.frontiersin.org

[3] K. Wolf and E. Stevens, "The role of rubrics in advancing and assessing student learning," The Journal of Effective Teaching, vol. 7, no. 1, pp. 3-14, 2007.

[4] P. Hudson, Analysing Pre-service Teachers' Rubrics for Assessing Students' Learning, 2005.

[5] M. Reddy, "Effect of rubrics on enhancement of student learning," Educate, vol. 7, no. 1, pp. 3-17, 2007.

[6] S. Winterscheid, "Rubrics: Effectiveness of feedback," BearWorks Institutional Repository, 2016.

[7] R. Wei and R. Pecheone, "Assessment for learning in pre-service teacher education," Teacher Assessment and the Quest for Teacher Quality: A Handbook, 2010.

[8] D. Atkinson and S. Lim, "Improving assessment processes in higher education: Student and teacher perceptions of the effectiveness of a rubric embedded in an LMS," Australasian Journal of Educational Technology, vol. 29, no. 5, 2013.

[9] E. Eshun and P. Osei-Poku, "Design students' perspectives on assessment rubric in studio-based learning," Journal of University Teaching \& Learning Practice, vol. 10, issue 1, article 8, 2013.

[10] A. Qasim and Z. Qasim, "Using rubrics to assess writing: Pros and cons in Pakistani teachers' opinions," Journal of Literature, Languages and Linguistics, vol. 16, 2015. 
[11] L. Chunhui, Constructing and Applying Rubrics in College-Level EFL Writing Assessment in China, 2018.

Copyright $\odot 2020$ by the authors. This is an open access article distributed under the Creative Commons Attribution License which permits unrestricted use, distribution, and reproduction in any medium, provided the original work is properly cited (CC BY 4.0).

Somyata Gupta is presently a master of education scholar at the University School of Education, Guru Gobind Singh Indraprastha University, Delhi, India. She is also a masters in English from MATS University and B2 Deutsch Zertifikat from Goethe Institut- Max Mueller Bhavan, India. Additionally, she has served as a high school English and
German language teacher. Her research interests include curriculum studies, teacher education, and assessment and evaluation.

Sangeeta Chauhan is a professor and former dean at Guru Gobind Singh Indraprastha University, Delhi, India. With teaching and research experience spread over 36 years, she has taught educational psychology, methods of teaching English and special education at the graduate and post graduate level. She has vast experience in presenting papers at the national and international conferences and seminars (IATE, Gnostic Centre, Jeevan Vigyan, MACESE, CIE, JMI). She is also a life member of Indian Association of Teacher Educators and All India Association for Educational Research. 